\title{
Reporting Bias of Dampness Problems and Smoking-A Result of Study Design
}

\author{
Malin Knutz ${ }^{*}$, Linda Hägerhed Engman², Thorbjörn Gustavsson², \\ Laura von Kobyletzki1,3, Carl-Gustaf Bornehag1,2 \\ ${ }^{1}$ Department of Health Science, Karlstad University, Karlstad, Sweden \\ ${ }^{2}$ Department of Building Physics and Indoor Environment, SP Technical Research Institute of Sweden, Borås, \\ Sweden \\ ${ }^{3}$ Institute of Clinical Research Lund University, Lund, Sweden \\ Email: ${ }^{*}$ malin.knutz@kau.se
}

Received 8 January 2014; revised 19 February 2014; accepted 5 March 2014

Copyright (C) 2014 by authors and Scientific Research Publishing Inc.

This work is licensed under the Creative Commons Attribution International License (CC BY).

http://creativecommons.org/licenses/by/4.0/

(c) (i) Open Access

\begin{abstract}
Using questionnaire is a common, efficient and cheap way to collect data in population-based epidemiological studies. However, there is a general trend of declining response rates leading to a higher risk for bias affecting the validity of results. Use of anonymous questionnaires and/or other ways of distributions, e.g. via schools instead of postal, may increase response rates, but can also lead to other types of systematic errors. This study indicates that results from cross-sectional questionnaire studies differ depending on distribution method and whether the survey is anonymous or not. Also the official purpose of the survey may affect the outcome. When studying wellknown risk-factors and health effects, potential methodological problems like reporting bias must be considered in cross sectional studies.
\end{abstract}

\section{Keywords}

Questionnaire; Asthma; Longitudinal Study; Home Environment; Children; Dampness; Smoking; Bias

\section{Introduction}

Using questionnaire is a common, efficient and cheap way to collect data in population-based epidemiological studies. Many studies investigating the prevalence of asthma and allergy among children, and associated riskfactors in the indoor environment have used self-administrated questionnaire data, including e.g., a large number

\footnotetext{
${ }^{*}$ Corresponding author.
}

How to cite this paper: Knutz, M., Engman, L.H., Gustavsson, T., von Kobyletzki, L. and Bornehag, C.-G. (2014) Reporting Bias of Dampness Problems and Smoking-A Result of Study Design. Open Journal of Preventive Medicine, 4, 107-115. 
of studies on moisture-related problems in homes and the risk for airway diseases [1]-[4]. However, there is a general trend that the response rates in questionnaire studies are declining and such a decreasing response rate can be seen in many parts of the world [5]-[7]. One possible reason for lower response rates could be that the number of studies (both scientifically based and those more commercially focused) have increased dramatically during the recent decade which might make people fatigue in answering surveys [8].

Low response rates are a risk to the quality and validity of the results in the study and can result in systematic errors that might affect the results. One problem is selection bias, when i.e. parents to allergic children might be more willing to respond to questionnaires focusing on asthma and allergy compared with parents with non-allergic children [9]. Furthermore, parents to children with allergies may also answer systematically differently compared with parents to children without allergy i.e. reporting bias. In combination with low response rate in a study with selection bias differential misclassification can bias results in either direction. Further the results will be difficult to generalize. Minimizing all these potential biases as well as increasing the response rates are known ways to obtain good data quality in questionnaire studies [7].

Lower response rates might be influenced by how the questionnaire is delivered. Questionnaires being delivered to young people via school and daycare settings is still considered to be a method with high response rate (80\% - 90\%), even though it has declined over the past 20 years [10] [11]. Another issue is that studies have shown that people tend to systematically answer in a different way in anonymous questionnaires compared to non-anonymous questionnaires, especially regarding sensitive health behaviors. Durant $e t$ al. [12] showed that non-anonymously assessment conditions can lead to reduced data quality where respondents in a non-anonymous study were less likely to report sensitive data such as sexual behavior compared with anonymous respondents. Another example is smoking, which is a well-known risk-factor for asthma and allergic symptoms in children, where respondents that smoke is less likely to answer truthfully compared to respondents that don't smoke [13].

Due to general declined response rates over the last decades and different ways of questionnaire deliveries, it is necessary to examine potential effects of data collection methods on research findings. Different ways of delivery, e.g. direct to the home by postal service or via personnel in daycare centers, might also have an influence on the response rate. A third hypothesis is that the introduction of the questionnaire to the respondents also might have an effect on the results if the study focuses on either the indoor environment in the home or the indoor environment at the daycare center.

The objective of the current paper is to investigate whether two studies using the same questionnaire, but different distribution methods and personal identifications differ regarding collected data on background information and health outcomes, as well as their associations with indoor environmental factors.

\section{Method}

\subsection{Study Population and Data Collection}

In the current paper two different studies investigating the indoor environment and health effects among preschool children aged 1 - 5 y in the county of Värmland in Sweden were compared. Similar questionnaire was distributed to different families within the same population in two different ways.

The first study in focus of this paper; Dampness in Building and Health (DBH) was aimed to investigate the association between indoor environmental factors in homes and asthma and allergy problems in children in Sweden. The DBH study includes four phases, which is described more in detail elsewhere [14]. This paper includes the first step in the DBH study where a postal questionnaire was sent to the parents of 14,077 children between 1 and 5 years of age in the county of Värmland in Sweden in year 2000. The DBH data was collected under non-anonymous conditions where postal address where used to send out the questionnaires. Three reminders were sent out to the parents, and the response rate after the first reminder was $36 \%$, after the second reminder $58 \%$ and finally after the last reminder the response rate reached $79 \%$. The study also received regional media attention. An analysis of non-responders showed no indications of selection bias in this baseline investigation [15]. In the current paper, the study group was selected from this first phase of the DBH study with the restriction of only consisting of children attending day care centers in the municipality of Karlstad $(n=2535)$. The response rate the group of children living in the municipality of Karlstad i.e. the population included in the current study was the same as for the whole population participating in DBH (79\%).

The second study in this paper, the day care center study, was conducted in year 2006. All parents to children 
aged 1 - 5 years attending daycare centers in the municipality of Karlstad, were invited via the personnel at the day care centers to participate in the day care center study. The prior aim of this study was to investigate the day care center environment and children's health, but with a first step handing out a baseline questionnaire about their home environment. Personnel at the daycare centers distributed the questionnaire to parents of 2334 children (response rate 74\%). The questionnaire was filled in anonymously. One patch reminder was awarded by the staff and a poster about the study was put up at each day care center.

\subsection{Questionnaire}

Questions on allergic symptoms were collected, following the questions in the ISAAC-study [16]. The health outcomes of interest in the current study were doctor diagnosed asthma, doctor diagnosed rhinitis and eczema. Doctor diagnosed asthma was defined as "Has your child been diagnosed with asthma by a doctor?", doctor diagnosed rhinitis as "Has your child been diagnosed with hay fever or rhinitis by a doctor?". Eczema was defined as "Has your child ever had an itchy rash (eczema), during last 12 month?".

Data on background factors such as age, sex, allergic symptoms and allergy in family, length of breastfeeding, and smoking habits in the family were collected using the same questions in the two studies. Information regarding age of entering daycare and time spent at the day care center (hours/week) was also collected. Further questions about home environmental conditions and characteristics e.g. type of dwelling, location of dwelling and technical data such as dampness and flooring material were also equally formulated in the two questionnaires.

\subsection{Statistics}

Differences in frequencies and prevalence between groups have been tested with Pearson's Chi-square test $\left(\chi^{2}\right)$. Associations between indoor environmental factors and symptoms and diseases in the child have been estimated by crude and adjusted odds ratios (ORs and aORs), and are expressed with 95\% confidence intervals. Adjusted odds ratios have been computed using logistic regression models. Adjustments have been made for age, sex, allergic symptoms in family and smoking in family. A p-value $<5 \%$ have been considered as statistical significant. For statistical analyses, SPSS 20.0 was used.

\subsection{Ethics}

The DBH-study was approved by the Local Ethics Committee in Örebro and the day care center study was approved by Scientific Ethics Committee at Karlstad University, Sweden.

\section{Results}

\subsection{Description and Comparison of Frequencies}

Table 1 describes the frequencies of background factors, health symptoms and exposure variables in both the DBH study and the day care center study. Boys and girls were equally distributed (50.5\% vs $49.5 \%$ ) and there were more children in the older age groups $(4-5,5-6$ y) than in the younger age groups $(1-2,2-3,3-4$ y) in both study populations. In terms of distribution of sex and age, there are no major differences between the two study populations. Percentage of smokers in the family was higher in the DBH study compared with the day care center study ( $23 \%$ vs $18 \%, p=0.000)$. In both studied populations, about two thirds of the children lived in single family houses and the children in the day care center study reported to live in more single family houses (SH) compared with the DBH study $(\mathrm{p}=0.000)$. The majority of both populations lived in urban areas, whereas children in the day care study center reported to live in more rural areas compared to the DBH study population $(p=0.000)$. About $80 \%$ of the children from both study populations spent more than 20 hours per week at the daycare center and the vast majority were introduced to day care center after one year of age.

In both the DBH study and the day care center study the most frequent self-reported symptoms were wheezing (26\%) and cough at night was reported in about $10 \%$ in both groups (Table 2). However, a higher number of children in the DBH study suffered of eczema compared to the day care center study ( $26.6 \%$ vs $19.5 \%, \mathrm{p}=0.000$ ). The frequency of doctor diagnosed asthma was $5.9 \%$ in the DBH study and slightly higher in the day care center study $(7.8 \%, \mathrm{p}=0.000)$. More than half of both study populations had at least one parent with allergic symptoms. 
Table 1. Description of the study population.

\begin{tabular}{|c|c|c|c|c|c|c|}
\hline & & \multicolumn{2}{|c|}{ DBH study } & \multicolumn{2}{|c|}{ Daycare study } & \multirow[t]{2}{*}{ p-value } \\
\hline & & \multicolumn{2}{|c|}{$\mathrm{n}=2123$} & \multicolumn{2}{|c|}{$\mathrm{n}=2334$} & \\
\hline \multirow[t]{2}{*}{ Sex } & Girls & 1072 & 50.5 & 1173 & 50.5 & \\
\hline & Boys & 1051 & 49.5 & 1152 & 49.5 & 0.983 \\
\hline \multirow[t]{5}{*}{ Age } & $1-2$ & 375 & 17.7 & 309 & 13.3 & \\
\hline & $2-3$ & 406 & 19.1 & 508 & 21.9 & \\
\hline & $3-4$ & 410 & 19.3 & 519 & 22.4 & \\
\hline & $4-5$ & 449 & 21.1 & 463 & 19.9 & \\
\hline & $5-6$ & 483 & 22.8 & 492 & 21.2 & 0.686 \\
\hline \multirow[t]{2}{*}{ Type of dwelling } & SH & 1275 & 61.5 & 1567 & 68.2 & \\
\hline & MH & 799 & 38.5 & 731 & 31.8 & 0.000 \\
\hline \multirow[t]{2}{*}{ Location of dwelling } & Rural & 185 & 9.0 & 327 & 14.2 & \\
\hline & Urban & 1860 & 91.0 & 1973 & 85.8 & 0.000 \\
\hline \multirow[t]{2}{*}{ Allergy in family } & No & 933 & 44.4 & 988 & 42.5 & \\
\hline & Yes & 1169 & 55.6 & 1336 & 57.5 & 0.211 \\
\hline \multirow[t]{2}{*}{ Smoking in family } & No & 1634 & 77.0 & 1898 & 81.3 & \\
\hline & Yes & 489 & 23.0 & 428 & 18.4 & 0.000 \\
\hline \multirow[t]{2}{*}{ Hours/week at daycare } & $<20$ & 415 & 19.5 & 460 & 22.6 & \\
\hline & $>20$ & 1708 & 80.5 & 1579 & 77.4 & 0.017 \\
\hline \multirow[t]{2}{*}{ Age of entry at daycare } & $<1 \mathrm{y}$ & 151 & 7.1 & 114 & 5.5 & \\
\hline & $>1 \mathrm{y}$ & 1962 & 92.9 & 1954 & 95.5 & 0.033 \\
\hline \multirow[t]{2}{*}{ Flooring material child's room } & All other & 894 & 45.8 & 1439 & 65.8 & \\
\hline & PVC & 1058 & 54.2 & 749 & 34.2 & 0.000 \\
\hline \multirow[t]{2}{*}{ Flooring material parents room } & All other & 1035 & 52.7 & 1564 & 71.3 & \\
\hline & PVC & 928 & 47.3 & 631 & 28.7 & 0.000 \\
\hline \multirow[t]{2}{*}{ Visible dampness } & No & 2013 & 98.7 & 2200 & 98.1 & \\
\hline & Yes & 27 & 1.3 & 42 & 1.9 & 0.146 \\
\hline \multirow[t]{2}{*}{ Window pane condensation } & No & 1640 & 85.7 & 1672 & 84.7 & \\
\hline & Yes & 274 & 14.3 & 301 & 15.3 & 0.390 \\
\hline \multirow[t]{2}{*}{ Moldy odor } & No & 1907 & 94.4 & 2103 & 94.8 & \\
\hline & Yes & 114 & 5.6 & 115 & 5.2 & 0.542 \\
\hline
\end{tabular}

Marked bold: significant differences within studied population (logistic regression model, p < 0.05).

About half of the parents reported to have PVC-flooring in the parent's or child's bedroom in the DBH study but in the day care center study this frequency was $30 \%(p=0.000$, Table 1$)$. The frequencies of reported dampness problems in the home were similar in both the DBH study and the daycare study. Window pane condensation (WPC) and moldy odor was reported in 15\% respectively $5 \%$ of the dwellings in both study populations. The frequency of visible dampness in the child's or parents' bedroom was slightly lower in the DBH study compared to the day care center study (1.3\% respectively $1.9 \%)$.

\subsection{Description and Comparison of Risk Factors between the Two Groups}

In both studies, the prevalence of wheezing, doctor diagnosed asthma and rhinitis were reported more among boys compared to girls who on the other hand had a higher prevalence of eczema (Table 2). Airway symptoms were reported more among the younger children, while the prevalence of eczema and doctor diagnosed rhinitis increased with age. Having a parent with allergic symptoms was associated with a significantly increased risk of 
Table 2. Description of the study population prevalence of asthma, rhinitis and eczema the association with allergic symptoms in family, sex, and age expressed as OR (95\% CI).

\begin{tabular}{|c|c|c|c|c|c|c|c|c|c|c|}
\hline \multirow[b]{2}{*}{ Symptoms } & \multirow[b]{2}{*}{$\begin{array}{c}\text { Study } \\
\text { population }\end{array}$} & \multicolumn{3}{|c|}{ OR (95\% CI) } & \multicolumn{6}{|c|}{ Age (\%) } \\
\hline & & $\begin{array}{c}\text { Prevalence } \\
\text { of symptoms n } \\
\text { (\%) }\end{array}$ & Sex/boys ${ }^{1}$ & $\begin{array}{l}\text { Allergic } \\
\text { symptoms } \\
\text { in parents }{ }^{1}\end{array}$ & $1-2 y$ & $2-3 y$ & $3-4 y$ & $4-5 y$ & $5-6 y$ & p-value ${ }^{2}$ \\
\hline \multirow[t]{2}{*}{$\begin{array}{l}\text { Wheezing last } 12 \\
\mathrm{~m}\end{array}$} & $\mathrm{DBH}$ & 401 (19.7) & $\begin{array}{c}1.49 \\
(1.20-1.86)\end{array}$ & $\begin{array}{c}1.91 \\
(1.52-2.40)\end{array}$ & 29.9 & 25.7 & 17.2 & 15.6 & 13.0 & 0.000 \\
\hline & Daycare & $408(17.2)$ & $\begin{array}{c}1.65 \\
(1.33-2.06)\end{array}$ & $\begin{array}{c}2.03 \\
(1.62-2.54)\end{array}$ & 22.7 & 19.7 & 18.5 & 15.8 & 13.2 & 0.000 \\
\hline \multirow[t]{2}{*}{ Wheezing ever } & $\mathrm{DBH}$ & $543(25.8)$ & $\begin{array}{c}1.51 \\
(1.24-1.84)\end{array}$ & $\begin{array}{c}1.91 \\
(1.55-2.35)\end{array}$ & 28.8 & 31.1 & 26.4 & 23.3 & 20.9 & 0.000 \\
\hline & Daycare & 609 (26.4) & $\begin{array}{c}1.67 \\
(1.39-2.02)\end{array}$ & $\begin{array}{c}1.53 \\
(1.27-1.85)\end{array}$ & 25.9 & 28.0 & 25.5 & 25.2 & 27.5 & 0.983 \\
\hline \multirow[t]{2}{*}{ Cough at night } & $\mathrm{DBH}$ & $201(9.6)$ & $\begin{array}{c}1.49 \\
(1.20-1.86)\end{array}$ & $\begin{array}{c}1.91 \\
(1.52-2.40)\end{array}$ & 11.5 & 12.5 & 7.4 & 7.4 & 9.6 & 0.070 \\
\hline & Daycare & 236 (10.3) & $\begin{array}{c}1.06 \\
(0.81-1.39)\end{array}$ & $\begin{array}{c}1.71 \\
(1.29-2.27)\end{array}$ & 12.5 & 11.5 & 10.0 & 9.1 & 8.8 & 0.043 \\
\hline \multirow[t]{2}{*}{ Doctor d. asthma } & $\mathrm{DBH}$ & 125 (5.9) & $\begin{array}{c}1.51 \\
(1.05-2.18)\end{array}$ & $\begin{array}{c}2.58 \\
(1.69-3.93)\end{array}$ & 3.2 & 7.2 & 6.4 & 7.2 & 5.5 & 0.297 \\
\hline & Daycare & $180(7.8)$ & $\begin{array}{c}1.88 \\
(1.37-2.58)\end{array}$ & $\begin{array}{c}1.69 \\
(1.23-2.32)\end{array}$ & 4.2 & 6.5 & 7.8 & 10.6 & 8.6 & 0.004 \\
\hline \multirow[t]{2}{*}{ Rhinitis last $12 \mathrm{~m}$} & $\mathrm{DBH}$ & 289 (13.9) & $\begin{array}{c}1.20 \\
(0.93-1.54)\end{array}$ & $\begin{array}{c}1.80 \\
(1.38-2.35)\end{array}$ & 15.3 & 14.1 & 15.1 & 12.4 & 13.0 & 0.233 \\
\hline & Daycare & $283(12.1)$ & $\begin{array}{c}1.06 \\
(0.83-1.36)\end{array}$ & $\begin{array}{c}2.06 \\
(1.58-2.69)\end{array}$ & 12.0 & 13.4 & 11.4 & 10.2 & 13.2 & 0.861 \\
\hline \multirow[t]{2}{*}{ Doctor d. rhinitis } & DBH & $58(2.8)$ & $\begin{array}{c}2.33 \\
(1.33-4.09)\end{array}$ & $\begin{array}{c}2.76 \\
(1.48-5.16)\end{array}$ & 0.5 & 1.5 & 1.2 & 3.8 & 5.8 & 0.000 \\
\hline & Daycare & $71(3.1)$ & $\begin{array}{c}1.18 \\
(0.74-1.89)\end{array}$ & $\begin{array}{c}2.59 \\
(1.52-4.40)\end{array}$ & 0.3 & 2.0 & 2.5 & 4.3 & 5.5 & 0.000 \\
\hline \multirow[t]{2}{*}{ Eczema last $12 \mathrm{~m}$} & DBH & 473 (22.3) & $\begin{array}{c}0.92 \\
(0.75-1.12)\end{array}$ & $\begin{array}{c}2.28 \\
(1.83-2.84)\end{array}$ & 16.8 & 22.7 & 24.9 & 25.6 & 20.9 & 0.128 \\
\hline & Daycare & $355(15.2)$ & $\begin{array}{c}0.89 \\
(0.71-1.11)\end{array}$ & $\begin{array}{c}1.92 \\
(1.52-2.44)\end{array}$ & 12.6 & 14.0 & 16.8 & 15.3 & 17.1 & 0.079 \\
\hline \multirow[t]{2}{*}{ Eczema ever } & $\mathrm{DBH}$ & $562(26.6)$ & $\begin{array}{c}0.96 \\
(0.79-1.17)\end{array}$ & $\begin{array}{c}2.05 \\
(1.67-2.51)\end{array}$ & 17.5 & 27.5 & 28.4 & 30.1 & 28.4 & 0.001 \\
\hline & Daycare & 451 (19.5) & $\begin{array}{c}0.93 \\
(0.75-1.14)\end{array}$ & $\begin{array}{c}1.90 \\
(1.53-2.35)\end{array}$ & 14.9 & 15.9 & 21.6 & 21.4 & 22.6 & 0.001 \\
\hline
\end{tabular}

Marked bold: ${ }^{1}$ Significant differences between reference category girls (ref) vs. boys; allergic symptoms in parents no vs. (ref) yes within studied population, $\mathrm{p}<0.05 .{ }^{2}$ Linear by linear association within studied population, $\mathrm{p}<0.05$.

all studied symptoms, similarly in both populations (OR = 1.47 - 2.79, Table 2).

In the day care center study, children with asthma and eczema were associated with attending more than 20 hours at the daycare center per week, while no significant association were seen in the DBH study (Table 3). Children who were introduced to daycare centers before one year of age showed a higher prevalence of doctor diagnosed asthma and rhinitis in both study populations, however only significant associations for doctor diagnosed asthma in the day care center study.

Smoking in family was significantly associated with doctor diagnosed asthma in the child in the day care center study, but this association was not seen in the DBH study (Table 3). Reports of moldy odor was significantly associated with more eczema in the DBH study (AOR 1.73; 95\% CI 1.14 - 2.63) but was not significant in day care center study (1.28; 0.78 - 2.10). Furthermore, in the DBH study, a significant association was found between WPC and doctor diagnosed asthma, and the same association with eczema was on the borderline of significance. WPC 
Table 3. Association between the prevalence of doctor diagnosed asthma, doctor diagnosed rhinitis and eczema 12 months, and daycare variables, smoking, dampness indices and flooring material in the DBH study and the daycare study. Associations expressed as AOR (95\% CI).

\begin{tabular}{|c|c|c|c|c|}
\hline & & AOR $(95 \% \text { CI })^{1}$ & AOR $(95 \% \text { CI })^{1}$ & $\operatorname{AOR}(95 \% \mathrm{CI})^{1}$ \\
\hline & & Doctor diagnosed asthma & Doctor diagnosed rhinitis & Eczema 12 m \\
\hline Type of dwelling & SH & 1.0 & 1.0 & 1.0 \\
\hline DBH study & MH & $1.17(0.79-1.73)$ & $1.52(0.87-2.67)$ & $1.21(0.97-1.52)$ \\
\hline Daycare study & MH & $1.10(0.75-1.61)$ & $1.69(0.98-2.92)$ & $1.27(0.96-1.67)$ \\
\hline Hours/week at daycare & $<20$ & 1.0 & 1.0 & 1.0 \\
\hline DBH study & $>20$ & $1.34(0.81-2.23)$ & $1.17(0.56-2.43)$ & $1.20(0.91-1.58)$ \\
\hline Daycare study & $>20$ & $1.93(1.22-3.06)$ & $1.40(0.70-2.79)$ & $2.03(1.44-2.88)$ \\
\hline Age of entry at daycare & $>1 \mathrm{y}$ & 1.0 & 1.0 & 1.0 \\
\hline DBH study & $<1 \mathrm{y}$ & $1.59(0.86-2.95)$ & $1.61(0.62-4.25)$ & $1.05(0.86-1.30)$ \\
\hline Daycare study & $<1 \mathrm{y}$ & $1.91(1.07-3.41)$ & $1.67(0.64-4.35)$ & $0.87(0.49-1.53)$ \\
\hline Smoking in family ${ }^{2}$ & No & 1.0 & 1.0 & 1.0 \\
\hline DBH study & Yes & $1.34(0.88-2.03)$ & $0.62(0.30-1.30)$ & $1.12(0.88-1.43)$ \\
\hline Daycare study & Yes & $1.93(1.36-2.74)$ & $1.25(0.69-2.24)$ & $1.14(0.85-1.53)$ \\
\hline Window pane condensation & No & 1.0 & 1.0 & 1.0 \\
\hline DBH study & Yes & $2.00(1.26-3.17)$ & $1.02(0.47-2.24)$ & $1.32(0.97-1.79)$ \\
\hline Daycare study & Yes & $0.84(0.52-1.36)$ & $1.04(0.50-2.16)$ & $1.03(0.73-1.45)$ \\
\hline Moldy odor & No & 1.0 & 1.0 & 1.0 \\
\hline DBH study & Yes & $1.34(0.65-2.74)$ & $0.33(0.04-2.43)$ & $1.73(1.14-2.63)$ \\
\hline Daycare study & Yes & $0.99(0.48-2.01)$ & $1.51(0.59-3.87)$ & $1.28(0.78-2.10)$ \\
\hline
\end{tabular}

was not associated with any of the studied symptoms in the daycare study. Due to a low frequency of reported visible dampness further analysis were not performed.

\section{Discussion}

The two compared studies in this paper had relatively similar and high response rates even though there were differences in delivery methods (postal with three reminders vs. daycare center with one reminder) and personal identification (non-anonymous vs. anonymous). Using reputable institutions such as daycare centers or schools as well as using anonymous questionnaires might result in higher response rates in studies which investigating children's health. However, when non-anonymous data is required, such as conducting a cohort study, postal questionnaires should be used.

Despite a time gap of six years between the two studies, there were few differences regarding reports of background factors and health status, meaning that comparisons of the two study populations is feasible. However, one could raise the question if a day care center population really is representative and comparable with a whole population included children in home care? In Värmland, more than $80 \%$ of the children over 1 year old attend daycare. In the DBH study we had the opportunity to access data from the larger cohort in the whole county of Värmland i.e. a database where also children not attending daycare are included. When comparing children attending daycare center (84\% of all children in Karlstad) in the city of Karlstad with all children in Värmland and with children with home care, no difference could be seen regarding background data such as age, sex, allergic symptoms in the child or allergy in family. One example is reports of wheezing during last 12 months, where the prevalence was $18.9 \%$ of the children in the whole DBH population in Värmland, while in children at daycare centers in Karlstad the prevalence was $19.7 \%$. This indicates that data from questionnaires distributed by the daycare centers is representative for the whole study population, including children not attending daycare.

One difference between the recruitment of the two study populations and distribution of the questionnaire is that the day care center study was anonymous and distributed via the daycare centers while the questionnaires 
for the DBH study were sent out to the subjects' postal address. Despite this, the questionnaire data from the compared study populations did not differ significantly regarding general background factors, indicating that the study populations were comparable. However, smoking in family was more reported in the DBH study in year 2000 and was lower in the day care center study in 2006 (23.0\% vs 18.4\%) which is in line with the Swedish Social Board report published in 2011 [17]. One could expect reported frequency of smoking habits would be the opposite, where an anonymous questionnaire would increase the willingness to report smoking more truthfully compared to a non-anonymous questionnaire. However, our results instead indicate that smoking has been decreasing over the years in families with children. Even though there is much evidence that smoking is a well-known risk factor for asthma in the child [13] [18] [19], results from the DBH study did surprisingly not show any associations between smoking and asthma in the child. However, the anonymous daycare study showed that there was a significant association between smoking in family and asthma in the child. As stated earlier [12], studies show that people tend to answer systematically different in non-anonymous studies compared with anonymous studies, especially when it comes to reports of risk factors for sensitive health behavior. One can raise the question if our results indicate that well-known risk factors, such as reports of smoking, might be more valid in an anonymous study where parents to children with asthma might report smoking more truthfully.

The frequency of reported home dampness in the two study populations did not differ. However, associations between reported dampness and the studied health outcomes were only significant in the DBH study, but not in the day care center study. One plausible explanation for these diverse results could be that the DBH study was specifically aimed and public communicated for investigating dampness problems in the home environment and its association with asthma and allergy among children, while the day care center study foremost was aimed for investigating the daycare environment, but with a first step handing out a baseline questionnaire about health of the children and home environment. One important aspect is that there is a general knowledge in the society about dampness as a plausible risk factor for asthma [4] which may bias the results on a study investigating dampness problems, especially if the study is foremost aimed on this topic. Parents to children with allergic problems is maybe trying to find a cause for their child's allergy and therefore systematically report more dampness problems, or are more attentive to such anomalies, in the homes compared to parents with non-allergic children. These results suggest that there is essential for the validity of the results in studies on how the participants were informed regarding the aim of the study, but also to acknowledge certain limitations with investigating well known risk factors in cross-sectional studies.

\section{Conclusion}

In conclusion, the current study shows that conducting cross sectional questionnaire studies can give different results depending on the way of distributing the questionnaire and if it is anonymous or not. The study confirms that performing questionnaire studies through reliable institution such as daycare centers is encouraging and motivating for parents to participate and also increase the chance of higher response rates. The response rate was as high as $73 \%$ even with only one reminder and also that the study was anonymous. Results did not show any difference in background factors between the two studied populations, even though sensitive health-related behaviors, such as smoking, expected to be higher reported in an anonymous study compared with a non-anonymous study. However, the association between reports of parental smoking and asthma in the child was only significant in the daycare-center study which indicates that well-known risk-factors for studied outcomes might be more valid in an anonymous study where parents to children with asthma might report smoking more truthfully compared with in a non-anonymous study. Furthermore, how the participants were informed regarding the aim of the study also seems to have an impact on the results in a study. This might have affected the results between the two studies of the associations between reports of dampness at home and health. Methodological problems like reporting bias is especially important to acknowledge when investigating well-known risk-factors and health effects at the same point time in cross-sectional studies.

\section{Acknowledgements}

Thanks to participating families. This study was supported by the Swedish Research Council for Environment, Agricultural Sciences and Spatial Planning (Formas) and SP Technical Research Institute of Sweden. 


\section{Conflict of Interest}

The authors declare no conflict of interest.

\section{References}

[1] Bornehag, C.G., Blomquist, G., Gyntelberg, F., Järvholm, B., Malmberg, P., Nordvall, L., Nielsen, A., Pershagen, G. and Sundell, J. (2001) Dampness in Buildings and Health. Nordic Interdisciplinary Review of the Scientific Evidence on Associations between Exposure to "Dampness" in Buildings and Health Effects (NORDDAMP). Indoor Air, 11, 72-86. http://dx.doi.org/10.1034/j.1600-0668.2001.110202.x

[2] Bornehag, C., Sundell, J., Bonini, S., Custovic, A., Malmberg, P., Skerfving, S., Sigsgaard, T. and Verhoeff, A. (2004) Dampness in Buildings as a Risk Factor for Health Effects, EUROEXPO: A Multidisciplinary Review of the Literature (1998-2000) on Dampness and Mite Exposure in Buildings and Health Effects. Indoor Air, 14, 243-257. http://dx.doi.org/10.1111/j.1600-0668.2004.00240.x

[3] Wickman, M., Kull, I., Pershagen, G. and Nordvall, S.L. (2002) The BAMSE Project: Presentation of a Prospective Longitudinal Birth Cohort Study. Pediatric Allergy and Immunology, 13, 11-13. http://dx.doi.org/10.1034/j.1399-3038.13.s.15.10.x

[4] Mendell, M.J., Mirer, A.G., Cheung, K., Tong, M. and Douwes, J. (2011) Respiratory and Allergic Health Effects of Dampness, Mold, and Dampness-Related Agents: A Review of the Epidemiologic Evidence. Environmental Health Perspectives, 119, 748-756. http://dx.doi.org/10.1289/ehp.1002410

[5] de Leeuw Ed., H.W. (2002) Trends in Household Survey Nonresponse: A Longitudinal and International Comparison. In: Groves, R.D.D., Eltinge, J. and Little, R., Eds., Survey Nonresponse, John Wiley \& Sons, New York, 41-54.

[6] Koshy, G. and Brabin, B.J. (2012) Parental Compliance-An Emerging Problem in Liverpool Community Child Health Surveys 1991-2006. BMC Medical Research Methodology, 12, 53. http://dx.doi.org/10.1186/1471-2288-12-53

[7] Morton, L.M., Cahill, J. and Hartge, P. (2006) Reporting Participation in Epidemiologic Studies: A Survey of Practice. American Journal of Epidemiology, 163, 197-203. http://dx.doi.org/10.1093/aje/kwj036

[8] Barclay, S., Todd, C., Finlay, I., Grande, G. and Wyatt, P. (2002) Not Another Questionnaire! Maximizing the Response Rate, Predicting Non-Response and Assessing Non-Response Bias in Postal Questionnaire Studies of GPs. Family Practice, 19, 105-111. http://dx.doi.org/10.1093/fampra/19.1.105

[9] Bornehag, C.G., Moniruzzaman, S., Larsson, M., Lindstrom, C.B., Hasselgren, M., Bodin, A., von Kobyletzkic, L.B., Carlstedt, F., Lundin, F., Nanberg, E., Jonsson, B.A., Sigsgaard, T. and Janson, S. (2012) The SELMA Study: A Birth Cohort Study in Sweden Following More than 2000 Mother-Child Pairs. Paediatric and Perinatal Epidemiology, 26, 456-467. http://dx.doi.org/10.1111/j.1365-3016.2012.01314.x

[10] Hagquist, C. (2012) Skolmiljö, Mobbning Och Hälsa-Resultat Från Ung i Värmland 1988-2011, Vol. 33. Karlstad University Studies, Karlstad.

[11] Svensson, B., Bornehag, C.G. and Janson, S. (2011) Chronic Conditions in Children Increase the Risk for Physical Abuse-But Vary with Socio-Economic Circumstances. Acta Paediatrica, 100, 407-412. http://dx.doi.org/10.1111/j.1651-2227.2010.02029.x

[12] Durant, L.E., Carey, M.P. and Schroder, K.E. (2002) Effects of Anonymity, Gender, and Erotophilia on the Quality of Data Obtained from Self-Reports of Socially Sensitive Behaviors. Journal of Behavioral Medicine, 25, 438-467. http://dx.doi.org/10.1023/A:1020419023766

[13] Burke, H., Leonardi-Bee, J., Hashim, A., Pine-Abata, H., Chen, Y., Cook, D.G., Britton, J.R. and McKeever, T.M. (2012) Prenatal and Passive Smoke Exposure and Incidence of Asthma and Wheeze: Systematic Review and MetaAnalysis. Pediatrics, 129, 735-744. http://dx.doi.org/10.1542/peds.2011-2196

[14] Bornehag, C.G., Sundell, J. and Sigsgaard, T. (2004) Dampness in Buildings and Health (DBH): Report from an Ongoing Epidemiological Investigation on the Association between Indoor Environmental Factors and Health Effects among Children in Sweden. Indoor Air, 14, 59-66. http://dx.doi.org/10.1111/j.1600-0668.2004.00274.x

[15] Bornehag, C.G., Sundell, J., Weschler, C.J. and Sigsgaard, T. (2005) Potential Selection Biases. Environmental Health Perspectives, 113, A152-153. http://dx.doi.org/10.1289/ehp.113-a152c

[16] Asher, M.I., Keil, U., Anderson, H.R., Beasley, R., Crane, J., Martinez, F., Mitchell, E.A., Pearce, N., Sibbald, B., Stewart, A.W., et al. (1995) International Study of Asthma and Allergies in Childhood (ISAAC): Rationale and Methods. European Respiratory Journal, 8, 483-491. http://dx.doi.org/10.1183/09031936.95.08030483

[17] Socialstyrelsen (2011) Breast-Feeding and Smoking Habits among Parents of Infants Born in 2009 (in Swedish).

[18] Gilliland, F.D., Berhane, K., McConnell, R., Gauderman, W.J., Vora, H., Rappaport, E.B., Avol, E. and Peters, J.M. (2000) Maternal Smoking during Pregnancy, Environmental Tobacco Smoke Exposure and Childhood Lung Function. Thorax, 55, 271-276. http://dx.doi.org/10.1136/thorax.55.4.271 
[19] Pattenden, S., Antova, T., Neuberger, M., Nikiforov, B., De Sario, M., Grize, L., Heinrich, J., Hruba, F., Janssen, N., Luttmann-Gibson, H., Privalova, L., Rudnai, P., Splichalova, A., Zlotkowska, R. and Fletcher, T. (2006) Parental Smoking and Children's Respiratory Health: Independent Effects of Prenatal and Postnatal Exposure. Tobacco Control, 15, 294-301. http://dx.doi.org/10.1136/tc.2005.015065 